among car occupants increased. And who were the young car occupants killed in the east? If some were West German residents (more likely to drive than young former East Germans) the population denominators used in the study of Winston et al would need to be reconsidered.

It is instructive also to look at other European countries. In 1995 (latest available data) the rate of all road deaths in men aged 15 -24 was 40.3 per 100000 in Germany, similar to the rate in West Germany before unification (38.4 in 1989). Neighbouring Poland had a rate in 1995 of 35.4, but in Greece it was 54.2. As long ago as 1949 Smeed showed that, for all countries, the road death rates per vehicle decrease as the number of vehicles increases, with many factors contributing, including driver experience and road design. ${ }^{3}$ Car design, by contrast, does not necessarily increase safety, especially for non-road users.
Yet emphasising injury prevention in car use ignores the bigger picture. Before unification West Germany had 7615 road deaths in 1989. Public transport incurs fewer deaths per kilometre travelled than do cars: reducing car ownership and promoting integrated transport can shift travel back to bus and rail. Promoting walking and cycling will have positive health benefits. ${ }^{4}$ And reducing the use of cars will help limit global warming and the effects which now threaten us all. ${ }^{5}$

Morris J. The uses of epidemiology. Edinburgh: Churchill Livingstone, 1975:237.

2 World Health Organisation. World health statistics. Geneva: WHO, 1991-8. Adams J. Risk and freedom. Cardiff: Transport Publishing Projects, 1985:24.

4 British Medical Association. Road transport and health. London: BMA, 1997.

5 Haines A, McMichael AJ. Climate change and health: the implications for research, monitoring and policy. BMJ 1997;315:870-4.

\title{
Prevention of vertical transmission of HIV: analysis of cost effectiveness of options available in South Africa
}

\author{
Neil Söderlund, Karen Zwi, Anthony Kinghorn, Glenda Gray
}

\section{Papers pp 1656,} 1660

Centre for Health Policy, University of the Witwatersrand PO Box 1038,

Johannesburg 2000,

South Africa

Neil Söderlund,

health economist

Department of

Paediatrics, Chris

Hani Baragwanath

Hospital,

Johannesburg,

South Africa

Karen Zwi,

senior lecturer

Abt Associates

South Africa,

Johannesburg,

South Africa

Anthony Kinghorn,

health economist

Perinatal HIV

Research Unit,

University of the

Witwatersrand,

Johannesburg,

South Africa

Glenda Gray,

director

Correspondence:

Dr Söderlund

soderlun@icon.

co.za

BMJ 1999;318:1650-6

\begin{abstract}
Objective To assess the cost effectiveness of vertical transmission prevention strategies by using a mathematical simulation model.

Design A Markov chain model was used to simulate the cost effectiveness of four formula feeding strategies, three antiretroviral interventions, and combined formula feeding and antiretroviral interventions on a cohort of 20000 pregnancies. All children born to HIV positive mothers were followed up until age of likely death given current life expectancy and a cost per life year gained calculated for each strategy.

Setting Model of working class, urban South African population.

Results Low cost antiretroviral regimens were almost as effective as high cost ones and more cost effective when formula feeding interventions were added. With or without formula feeding, low cost antiretroviral interventions were likely to save lives and money. Interventions that allowed breast feeding early on, to be replaced by formula feeding at 4 or 7 months, seemed likely to save fewer lives and offered poorer value for money.

Conclusions Antiretroviral interventions are probably cost effective across a wide range of settings, with or without formula feeding interventions. The appropriateness of formula feeding was highly cost effective only in settings with high seroprevalence and reasonable levels of child survival and dangerous where infant mortality was high or the protective effect of breast feeding substantial. Pilot projects are now needed to ensure the feasibility of implementation.
\end{abstract}

\section{Introduction}

Whereas paediatric HIV infection is on the verge of being eliminated in the United States, in sub-Saharan Africa it has become a common cause of admission to hospital and a major contributor to childhood mortality. ${ }^{1}$ The results of recent studies showing the efficacy of short course antiretroviral treatment for the prevention of vertical transmission of HIV in breastfed and formula fed infants has led to debate around their more widespread introduction internationally. ${ }^{2-4}$

For some years now, developed countries have had in place cost effective methods to prevent the vertical transmission of HIV. ${ }^{5}$ In developing countries, however, these interventions have not been offered on a routine basis. The main reason for this is the perceived high cost of transmission prevention programmes rather than lack of evidence of effectiveness. Interventions that seem to reduce vertical transmission in developed and developing countries include substitution of formula feeding for breast feeding ${ }^{6}$ and administration of antiretroviral agents to mother and child around the time of birth. ${ }^{2-4-9}$ Caesarean section significantly reduces vertical transmission, ${ }^{10}$ although cost effectiveness is not established even in developed countries $^{11}$ and it is unclear how feasible elective caesarian sections are in areas with poor resources. Other interventions, such as the use of vaginal antiseptics before delivery and the administration of vitamin A with or without micronutrients, have yet to be conclusively evaluated. ${ }^{12}{ }^{13}$

For policymakers the health and economic benefits of avoiding childhood HIV infection need to be balanced against the costs of implementing vertical transmission prevention programmes and any adverse effects that may be incurred through such 
Potential benefits, costs, and adverse effects associated with antiretroviral and formula feeding interventions

Benefits of intervention

Lives saved

Morbidity averted and quality of life improvements Prevention of costs of future health care related to HIV infection

Decreased burden of care on families

Adverse effects of intervention

Increased anxiety associated with HIV positive status Stigma attached to HIV positive status and social consequences thereof

Spread of recommendation to formula feed beyond mothers known to be infected with HIV

Abuse of antiretroviral drugs

Costs of intervention

Costs of screening and counselling

Costs of health worker training

Costs due to loss to follow up and poor compliance with interventions

Costs of drugs for antiretroviral regimens

Mortality, morbidity, and healthcare costs associated with formula feeding in HIV negative infants

programmes. ${ }^{14}$ South Africa is no exception. With more than 1 in 5 women attending antenatal clinics nationally testing positive for HIV in 1998 (Department of Health press release, February 1999), both the benefits of infection avoided and the costs of intervention are likely to be considerable and hence the penalty for wrong decisions substantial. Many factors need to be taken into account in considering this type of intervention; some of these are outlined in the box.

This study sought to develop a method to inform such decisions by using a mathematical simulation model approach. The study objective was to compare the likely cost effectiveness of different strategies to prevent vertical transmission such as antiretroviral treatment and artificial feeding alone and in combination in an urban working class population in South Africa. While we believe that the model can be generalised to many settings globally, it was applied to this particular context because of easy availability of verifiable data and the immediate requirements of policymakers in South Africa.

Several evaluations of cost effectiveness in developing countries have been undertaken recently. Marseilles and others ${ }^{15}$ and Mansergh et $\mathrm{al}^{16}$ did not assess combined interventions and the latter study used HIV infection rather than mortality as its outcome of interest. Mansergh et $\mathrm{al}^{16}$ and Wilkinson et $\mathrm{al}^{17}$ estimated cost effectiveness before the efficacy of the short course treaments had been shown. The regimens were therefore more costly and more difficult to implement than short course regimens, which have now been proved to be effective.

\section{Methods}

We applied a Markov chain simulation model to the problem outlined above. This approach attempts to replicate the natural course of transmission and disease by simulating transitions between discrete disease states. In this case, unborn children were assumed to progress from uninfected to infected to dead states. The rates of transition between these states were determined by environmental and interventional parameters specified in the model. A cohort of 20000 pregnancies occurring over a period of 1 year, reflecting the approximate number of births in the community studied, were simulated. The children from these pregnancies born to HIV positive women were followed either until their predicted age of death according to current life expectancy data (for HIV negative children) or until their death due to HIV infection (for HIV infected children). Costs, morbidity, and mortality were simulated for the birth cohort with seven different intervention strategies and a control strategy of no intervention (box). In addition, combinations of the more favourable interventions were modelled. Model transitions occurred on a monthly basis for the first 9 years of life and then on an annual basis until death. Model hazard functions generally followed Weibull distributions that were fitted to best available data from settings similar to the one under study.

The model was applied to the Soweto community, a black, urban, working class population of about 1 million people located south west of central Johannesburg. The community is served mainly by a single public hospital, the Chris Hani Baragwanath hospital, which has over 3000 beds. As far as possible all data were drawn to reflect this community and the hospital serving it. Table 1 outlines the main model assumptions, and the full set of model inputs are detailed in the $B M J$ website version of this paper. All costs are expressed in US dollars (converted for South African rands at the 1998 rate of $\mathrm{R} 6=\$ 1$ ) and where necessary $£$ (at $\$ 1.5=£ 1$ ). More details on the derivation of cost data are given elsewhere ${ }^{26}$ Rates of use and associated costs of health care for HIV infected children were estimated from data recorded on all paediatric admissions to the hospital between 1992 and 1997, during which time the proportion of paediatric admissions infected with HIV increased from $2.9 \%$ to $20 \%{ }^{27}$ The denominator population of HIV infected children to which these utilisation and cost data applied was calcu-

Interventions assessed by simulation model

- Control-no intervention

- Counselling, screening, and, when mothers are HIV positive:

- Formula feeding recommended from birth

- Formula feeding recommended from 4 months only

- Formula feeding recommended from 7 months only

- Formula feeding recommended from birth; formula and bottles supplied

- ACTG076 regimen* (zidovudine before, during, and after birth) ${ }^{8}$

- PETRA arm B regimen*⿻ (zidovudine plus lamivudine, during and after birth)

- CDC-Thai regimen* (zidovudine before and during birth ${ }^{18}$

*These assume that the relevant antiretroviral course was followed, but no attempt was made to influence feeding.

†Saba J, 6th conference on retroviruses and opportunistic infections, Chicago, 1999. 
Table 1 Model parameters, data sources and values used in model

\begin{tabular}{|c|c|c|}
\hline Parameter & Source & Values used \\
\hline \multicolumn{3}{|l|}{ Base case data } \\
\hline HIV infection rates & $\begin{array}{l}\text { Department of Health and Population } \\
\text { Development } 1996^{19}\end{array}$ & $15 \%$ \\
\hline Infant mortality & Harrison and Nielson $1995^{20}$ & 35/1000 live births \\
\hline Discount rate & World Bank $1993^{21}$ & $5 \%$ \\
\hline Natural rates of breast feeding & Wagstaff et al $1993^{22}$; Ross et al $1983^{23}$ & $\begin{array}{l}\text { Proportion who breast feed from birth }=95 \% \text {; likelihood of stopping } \\
\text { breast feeding } / \text { month }=14 \%\end{array}$ \\
\hline \multicolumn{3}{|l|}{ Vertical transmission of HIV } \\
\hline $\begin{array}{l}\text { Proportion of infants born to HIV positive mothers infected at birth: } \\
\text { no intervention }\end{array}$ & Gray et al $1997^{\star}$ & $26 \%$ \\
\hline $\begin{array}{l}\text { Proportion of infants born to HIV positive mothers infected at birth: } \\
\text { antiretroviral interventions }\end{array}$ & $\begin{array}{l}\text { Centers for Disease Control } 1998^{18} \text {; Mayaux et al } \\
1997^{9} \text {; Saba } 1999 \dagger\end{array}$ & $\begin{array}{l}\text { CDC regimen }=13 \% \text { ( } 50 \% \text { reduction); ACTG076 regimen }=8 \%(70 \% \\
\text { reduction); PETRA regimen=16\% ( } 37 \% \text { reduction) }\end{array}$ \\
\hline $\begin{array}{l}\text { Risk of transmitting the virus by breast feeding (cumulative): age } \\
\text { specific rates derived from Weibull decay curve }\end{array}$ & Gray et al $1997^{\star}$ & $\begin{array}{l}\text { Cumulative infection risk: } 3 \text { months=10\%, } 6 \text { months }=13 \% \text {, } \\
12 \text { months }=16 \%, 18 \text { months }=17 \%\end{array}$ \\
\hline \multicolumn{3}{|l|}{ Survival } \\
\hline $\begin{array}{l}\text { HIV infected children: Weibull survival curve calibrated to survival } \\
\text { data from Uganda and South Africa (figures are numbers surviving } \\
\text { at end of period } \ddagger \text { ) }\end{array}$ & Spira and Msellati 1997§; Gray et al 1995ף & 1 year $=66 \%, 2$ year $=46 \%, 3$ year $=33 \%, 4$ year $=24 \%, 8$ year $=9 \%$ \\
\hline Uninfected children: life expectancy at birth & Central Statistical Service $1997^{24}$ & 66 years \\
\hline $\begin{array}{l}\text { Relative risk of mortality due to not breast feeding in HIV negative } \\
\text { children (relative risks of health care use assumed to be same as } \\
\text { for mortality) }\end{array}$ & Cunningham et al $1991^{25 * *}$ & $0-3$ months $=2.5,3-6$ months $=2.0,6-12$ months $=1.5$ \\
\hline \multicolumn{3}{|l|}{ Cost data } \\
\hline $\begin{array}{l}\text { Unit costs of counselling, screening, antiretroviral drugs, and } \\
\text { formula feed }\end{array}$ & Kinghorn et al $1998^{26}$ & $\begin{array}{l}\text { Counselling and screening=\$7.30 (£4.86) per pregnant woman; } \\
\text { antiretroviral drugs=from } \$ 400(£ 267) \text { (ACTG076) to } \$ 89 \text { ( } 559) \\
\text { (PETRA regimen) per person; formula feed and bottles ( } 6 \text { month } \\
\text { period) } \$ 60 \text { (£40) }\end{array}$ \\
\hline Average public healthcare expenditure on HIV positive children & $\begin{array}{l}\text { Zwi } 1999^{27} ; \text { Söderlund } 1997^{28} ; \text { Söderlund and } \\
\text { Peprah } 1998^{29} ; \text { Brown and van den Heever } 1994^{30}\end{array}$ & $\begin{array}{l}\text { Range of } 4 \text { to } 18 \text { days of hospitalisation required per year depending } \\
\text { on age; cost of hospitalisation }=\$ 57 \text { ( } £ 38 \text { ) per day; cost of outpatient } \\
\text { attendances }=\$ 48-\$ 183 \text { ( } £ 32-£ 122 \text { ) per year depending on age }\end{array}$ \\
\hline Average public healthcare expenditure per HIV negative child & $\begin{array}{l}\text { Söderlund and Peprah } 1998^{29} \text {; ReHMIS dataset } \\
1995^{31} \text {; Brown and van den Heever } 1994^{30}\end{array}$ & $\begin{array}{l}\text { 1-12 months old }=\$ 72(£ 48) \text { per year; } \geqslant 1 \text { year olds }=\$ 8.30(£ 5.5) \\
\text { per year }\end{array}$ \\
\hline
\end{tabular}

*Gray GE, McIntyre JA, Lyons SF, XIth international conference on AIDS, Vancouver, 1997. †Saba J, 6th conference on retroviruses and opportunistic infections, Chicago, 1999. fUse of Weibull distribution to model hazards implies that hazards were different for every month since birth. These were calibrated to cumulative survival data derived from sources mentioned; calibration source figures are shown in right hand column. §Spira R, Msellati P. Care of HIV infected children in developing countries: a workshop for clinical research, Paris, 1997.

१Gray GE, McIntyre JA, Pettifor JM, IXth international conference on AIDS and STD in Africa, Kampala, 1995. ** It was not possible to extract exact figure from this review article because of differences in nature of adverse events measured by different studies. Figures used represent reasonable estimate of overall risk of mortality on basis of review data.

lated by using a simple survival model and data from serology surveys of antenatal clinics from the preceding 7 years.

The cost effectiveness of each intervention was calculated relative to the control group as $(\mathrm{IC}+\mathrm{NC}-\mathrm{HC}) /(\mathrm{LS} * \mathrm{LE}-\mathrm{LL} * \mathrm{LE})$; where $\mathrm{IC}=$ intervention costs, $\mathrm{NC}=$ healthcare costs because of additional morbidity in formula fed children not infected with $\mathrm{HIV}, \mathrm{HC}=$ costs of $\mathrm{HIV}$ related care avoided by preventing infections, $\mathrm{LS}=$ lives saved by prevention of HIV infection, $\mathrm{LL}=$ lives lost because of formula feeding in children not infected with HIV, and $\mathrm{LE}=$ life expectancy.

Results were obtained in terms of costs per life year saved. Future costs and benefits were discounted at a rate of $5 \%$ per year. ${ }^{21}$ Health benefits and losses due to morbidity avoided or caused were ignored as their effect was negligible compared with that of mortality. Likewise, costs to family members of caring for sick children were not included because no data were available.

\section{Results}

One of the advantages of a Markov simulation approach is that it allows simultaneous estimation of likely costs and effectiveness associated with a given intervention. ${ }^{32}$ For simplicity, however, results are described here as effectiveness, costs, and cost effectiveness.

\section{Effectiveness of interventions}

Effectiveness was measured in terms of discounted life years saved and deaths averted.These represented the difference in years of life achieved and deaths, respectively, between the control and intervention populations. Figure 1 shows the net number of discounted deaths averted for each year after birth of the simulated cohort. The ACTG076 regimen is the most effective antiretroviral regimen but is only marginally more effective than the CDC-Thai regimen because of relatively lower levels of uptake attributable to the long and complicated administration requirements of the ACTG076 regimen. Whereas the number of lives saved from prevention of prepartum and intrapartum HIV peak in the first year of follow up, the net deaths prevented by formula feeding interventions tend to be later on (the model suggests that they peak in year 2). This is partly because of the later onset of HIV disease and partly because lives saved by formula feeding in the first year are offset by lives lost due to the lack of protective effect of breast milk in HIV negative children. The model suggests that options that recommend breast feeding early on, with a change to formula feeding after 3 or 6 months, save the least number of lives as most HIV transmission through breast milk seems to occur early on. ${ }^{2} 3334$

\section{Costs}

The costs of administering each of the interventions were estimated for 20000 pregnancies over a 1 year period. They include both annualised capital and recurrent costs and have been broken down into the costs of screening and counselling (which were essentially the same for all interventions) and the costs 


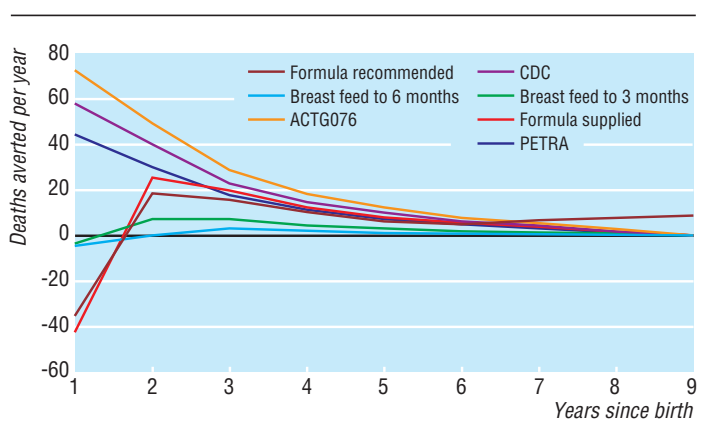

Fig 1 Discounted deaths prevented by year after birth and mode of intervention

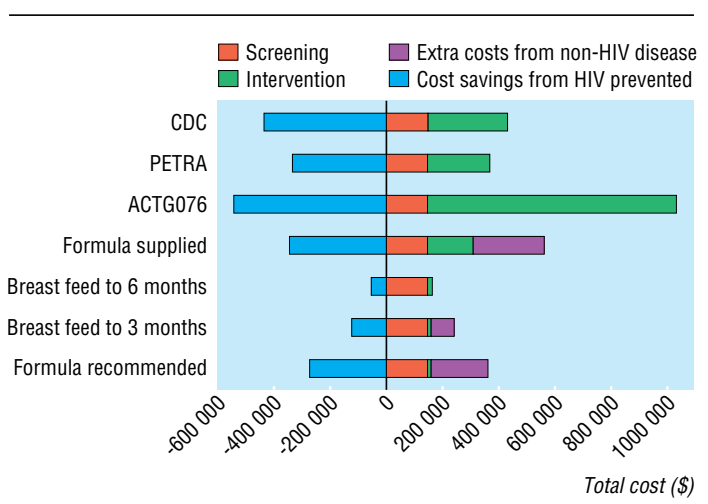

Fig 2 Costs of interventions, HIV cases prevented, and disease other that HIV caused by each intervention for simulated cohort of 20000 pregnancies $(\$ 1.5=£ 1)$

of the intervention itself, which included the costs of antiretroviral drugs, additional monitoring tests required, formula feeds, bottles, and staff time required for administering interventions. Figure 2 shows these costs, together with costs incurred because of increased incidence of diseases other than HIV caused by decreased breast feeding and savings due to illness prevented from HIV infection. The ACTG076 regimen is the most costly strategy by a considerable margin, and more than $80 \%$ of costs are due to expenditure on antiretroviral drugs and their administration. All of the strategies involving formula feeding from birth result in considerable costs because of disease other than HIV. Cost savings due to HIV infection averted are in line with relative effectiveness estimates.

\section{Cost effectiveness}

The cost effectiveness of each of the interventions is given in table 2. The World Development Report suggested that interventions costing less than $\$ 100(£ 67)$ per life year saved are cost effective for middle income countries. ${ }^{21}$ Cost effectiveness is estimated for indi- vidual and combined interventions. The CDC-Thai regimen alone and the CDC-Thai combined with formula feeding from birth at least pay for themselves in terms of costs of care avoided. The delayed formula feeding strategies do not seem to be particularly cost effective. The intrapartum and postpartum PETRA regimen is less cost effective than the CDC-Thai regimen but in overall terms still represents good value for money. It does not require antiretroviral treament until labour and might thus be the most feasible option when women present late in pregnancy or in labour.

Table 3 presents a one way sensitivity analysis for six model inputs: rates of antenatal seroprevalence, infant mortality, relative risk of death due to not breast feeding, cost of antiretroviral drugs, levels of expenditure on child health services, and uptake of antenatal HIV screening. The cost effectiveness of interventions is most sensitive to differences in rates of antenatal seroprevalence, with all showing improved cost effectiveness as rates increase. Formula feeding strategies are especially sensitive to rates of seroprevalence. When breast feeding is associated with a strong protective effect or when infant mortality exceeds around 70-140 per 1000, formula feeding interventions are contraindicated. The CDC-Thai and PETRA regimens are cost saving even at 1997 market prices in South Africa, and the reduction of antiretroviral prices to a quarter of their current level would make even the ACTG076 regimen reasonably cost effective. Model results are moderately sensitive to changes in expenditure on child health services. In our study population, if the level of spending were one quarter of what it currently is, the low cost antiretroviral regimens would still cost less than $\$ 100$ (£67) per life year saved. Interestingly, the cost effectiveness of formula feeding interventions tends to worsen as levels of expenditure increase because of the costs associated with treating increased illness in HIV negative children.

An incremental cost effectiveness analysis (table 4) shows the additional costs incurred and lives saved by changing to successively more effective (and expensive) intervention strategies. Changing from the cheapest antiretroviral treatment (PETRA) to the CDC-Thai regimen results in savings in terms of both lives and costs, as does adding a recommendation to formula feed. Providing formula in addition to simply recommending formula feeding is relatively expensive, however, at almost $\$ 1000$ (£667) per extra life year saved. Substituting the more effective ACTG076 antiretroviral regimen for the CDC-Thai one would save one extra life year for every $\$ 4000$ (£2667) spent.

\section{Discussion}

We have attempted to develop a generally applicable simulation model for assessing the effectiveness and cost effectiveness of interventions to prevent mother to

Table 2 Cost effectiveness (in \$) of interventions assessed ( $\$ 1.5=£ 1$ )

\begin{tabular}{lccccrrrrr} 
Detail & $\begin{array}{c}\text { Formula } \\
\text { recommended }\end{array}$ & $\begin{array}{c}\text { Breast feed } \\
\text { to } \mathbf{3} \text { months }\end{array}$ & $\begin{array}{c}\text { Breast feed } \\
\text { to } \mathbf{6} \text { months }\end{array}$ & $\begin{array}{c}\text { Formula } \\
\text { supplied }\end{array}$ & ACTG076 & PETRA & CDC & $\begin{array}{c}\text { CDC + formula } \\
\text { recommended }\end{array}$ & $\begin{array}{c}\text { CDC + formula } \\
\text { supplied }\end{array}$ \\
\hline Total deaths averted & 26 & 25 & 5 & 37 & 200 & 124 & 160 & 188 \\
\hline Total life years saved & 461 & 449 & 98 & 661 & 3655 & 2260 & 2926 & 3434 \\
\hline Total cost (000s) & 92 & 116 & 108 & 218 & 488 & 31 & -5 & -66 & 200 \\
\hline Cost per death averted & 3600 & 4700 & 20052 & 5967 & 2441 & 252 & CS & CS & 6654 \\
\hline Cost per life year saved & 200 & 258 & 1111 & 331 & 134 & 14 & CS & CS & 37 \\
\hline
\end{tabular}

CS=cost saving. 
Table 3 Sensitivity analysis. Figures are cost (in \$) per life year saved (\$1.5=£1)

\begin{tabular}{|c|c|c|c|c|c|c|c|c|c|}
\hline Detail & $\begin{array}{c}\text { Formula } \\
\text { recommended }\end{array}$ & $\begin{array}{l}\text { Breast feed } \\
\text { to } 3 \text { months }\end{array}$ & $\begin{array}{l}\text { Breast feed } \\
\text { to } 6 \text { months }\end{array}$ & $\begin{array}{l}\text { Formula } \\
\text { supplied }\end{array}$ & ACTG076 & PETRA & CDC & $\begin{array}{l}\mathrm{CDC}+\text { formula } \\
\text { recommended }\end{array}$ & $\begin{array}{l}\text { CDC + formula } \\
\text { supplied }\end{array}$ \\
\hline \multicolumn{10}{|c|}{ Antenatal HIV seroprevalence (\%): } \\
\hline 0.1 & 34319 & 35175 & 161533 & 24183 & 4462 & 6983 & 5393 & 4608 & 4393 \\
\hline 1 & 3580 & 3624 & 16351 & 2726 & 583 & 712 & 548 & 478 & 511 \\
\hline 2 & 1860 & 1865 & 8273 & 1523 & 365 & 360 & 276 & 244 & 291 \\
\hline 5 & 794 & 793 & 3394 & 771 & 225 & 141 & 104 & 92 & 146 \\
\hline 10 & 383 & 409 & 1715 & 471 & 165 & 54 & 33 & 21 & 77 \\
\hline 15 & 200 & 258 & 1111 & 331 & 134 & 14 & CS & CS & 37 \\
\hline 20 & 74 & 166 & 775 & 230 & 109 & CS & CS & CS & 4 \\
\hline 30 & CS & 41 & 374 & 67 & 68 & CS & CS & CS & CS \\
\hline 40 & CS & CS & 107 & CS & 30 & CS & CS & CS & CS \\
\hline \multicolumn{10}{|c|}{ Infant mortality (change relative to base rate): } \\
\hline 0.25 & 129 & 146 & 380 & 92 & 132 & 14 & CS & CS & 25 \\
\hline 0.5 & 147 & 168 & 469 & 121 & 133 & 14 & CS & CS & 28 \\
\hline 1 & 200 & 258 & 1111 & 331 & 134 & 14 & CS & CS & 37 \\
\hline 2 & 701 & DC & $D C$ & $\mathrm{DC}$ & 135 & 14 & CS & CS & 109 \\
\hline 4 & DC & $\mathrm{DC}$ & $\mathrm{DC}$ & $\mathrm{DC}$ & 139 & 14 & CS & DC & $\mathrm{DC}$ \\
\hline
\end{tabular}

Relative risk of death in non-breastfed, HIV negative children (change relative to base rate):

\begin{tabular}{|c|c|c|c|c|c|c|c|c|c|}
\hline 0.5 & 121 & 151 & 482 & 113 & 135 & 14 & CS & CS & 27 \\
\hline 1 & 200 & 258 & 1111 & 331 & 134 & 14 & CS & CS & 37 \\
\hline 2 & DC & DC & DC & DC & 131 & 13 & CS & CS & 142 \\
\hline 4 & DC & DC & $\mathrm{DC}$ & $\mathrm{DC}$ & 125 & 13 & CS & DC & DC \\
\hline \multicolumn{10}{|c|}{ Cost of antiretroviral drugs (change relative to base rate): } \\
\hline 1 & 200 & 258 & 1111 & 331 & 134 & 14 & CS & CS & 37 \\
\hline 0.5 & 200 & 258 & 1111 & 331 & 51 & CS & CS & CS & CS \\
\hline 0.25 & 200 & 258 & 1111 & 331 & 9 & CS & CS & CS & CS \\
\hline \multicolumn{10}{|c|}{ Expenditure on health services for HIV negative and positive children (change relative to base rate): } \\
\hline 0.25 & 151 & 256 & 1361 & 287 & 206 & 86 & 71 & 35 & 86 \\
\hline 0.5 & 167 & 257 & 1277 & 301 & 182 & 62 & 46 & 17 & 69 \\
\hline 1 & 200 & 258 & 1111 & 331 & 134 & 14 & CS & CS & 37 \\
\hline 2 & 266 & 261 & 777 & 389 & 37 & CS & CS & CS & CS \\
\hline 4 & 397 & 266 & 110 & 506 & CS & CS & CS & CS & CS \\
\hline \multicolumn{10}{|c|}{ Uptake of screening (proportion of women accepting): } \\
\hline 0.25 & $\mathrm{DC}$ & 3610 & $\mathrm{DC}$ & 6935 & 182 & 92 & 59 & 35 & 129 \\
\hline 0.5 & 518 & 506 & $\mathrm{DC}$ & 583 & 148 & 38 & 16 & CS & 62 \\
\hline 0.75 & 253 & 308 & 1877 & 379 & 137 & 20 & 3 & CS & 43 \\
\hline 0.9 & 200 & 258 & 1111 & 331 & 134 & 14 & CS & CS & 37 \\
\hline 1 & 177 & 236 & 893 & 309 & 132 & 11 & CS & CS & 34 \\
\hline
\end{tabular}

$\mathrm{CS}=$ cost saving. $\mathrm{DC}=$ net increase in deaths (death causing).

child transmission of HIV and to apply this to a particular context with which we were familiar. We are confident that administration of a low cost antiretroviral regimen or advocating formula feeding for infants of HIV infected women, or both, would save lives and, in many cases, save money as well. Provision of formula feed seems to be relatively expensive given the modest increase in effectiveness that it generates. The delayed formula feeding strategies and the ACTG076 regimen have little to recommend them in South Africa. By comparison, however, a recent report estimates that triple antiretroviral treament for HIV disease costs about $\$ 10000$ ( $£ 6667$ ) per life year saved, adjusted for disability. ${ }^{35}$

\section{Affordability and feasibility}

Aside from cost effectiveness, issues to consider in the introduction of antiretroviral interventions into health systems include affordability, availability of human resources, and infrastructure, equity, and acceptability. It has been estimated that the cost of setting up and running a programme to provide the CDC-Thai regimen to HIV infected women in South Africa at a national level is less than $0.5 \%$ of the health budget. ${ }^{26}$ Combined with our assessment that the intervention is likely to be cost saving, and the enormous social, economic, and health system burden imposed by having to care for sick children infected with HIV, such absolute cost levels tend to refute the claim of

Table 4 Incremental cost effectiveness analysis of most favourable interventions

\begin{tabular}{|c|c|c|c|c|c|}
\hline Detail & $\begin{array}{l}\text { PETRA regimen } \\
\text { (option 1) }\end{array}$ & $\begin{array}{l}\text { Change to CDC regimen from } \\
\text { option } 1 \text { (option 2) }\end{array}$ & $\begin{array}{l}\text { Add formula feeding recommendation } \\
\text { to option } 2 \text { (option } 3 \text { ) }\end{array}$ & $\begin{array}{l}\text { Provide free formula for } \\
\text { option } 3 \text { (option 4) }\end{array}$ & $\begin{array}{l}\text { Substitute ACTG076 for CDC } \\
\text { regimen in option } 2 \text { (option 5) }\end{array}$ \\
\hline Extra deaths averted & 124 & 36 & 28 & 12 & 40 \\
\hline Extra life years saved & 2260 & 666 & 508 & 220 & 730 \\
\hline Cost per additional death averted $(\$)$ & 252 & -286 & -2151 & 16510 & 74202 \\
\hline Cost per additional life year saved $(\$)$ & 14 & -16 & -119 & 910 & 4059 \\
\hline
\end{tabular}


Wilkinson et al that strategies to prevent transmission of HIV are unaffordable in South Africa. ${ }^{17}$

Furthermore, primary healthcare clinics and hospitals in urban and much of rural South Africa probably already have the capacity to do rapid testing and implement short course oral antiretroviral treatment. Healthcare workers will need additional training on education about HIV, infant feeding practices, and skills required for counselling before and after HIV diagnosis, and these have been included in the costs incurred in our model. A number of challenges are likely to remain in implementing such a programme, including overburdened clinic staff, issues surrounding confidentiality and disclosure, and security around the distribution of drugs or formula feeds, or both. Our data support the need for piloting such interventions to understand feasibility and acceptability issues better.

Setting up an intervention to reduce vertical transmission of HIV may have important secondary benefits, including opportunities to reduce further heterosexual transmission by motivating women to practise safer sex, preventing acquisition of HIV infection in those identified as negative, and protecting partners in those who are positive. Knowledge of the risk of transmission to the babies of HIV infected women allows for vigilant follow up care of the infants and prophylactic medication to prevent opportunistic infections. These benefits have not been quantified in developing countries and hence are not included in the model.

Critics have raised the problem and the associated costs of increased numbers of orphans if children are protected from perinatal transmission. Infected children, whether they are orphans or not, however, incur substantial costs to the health system because of repeated admissions, longer length of hospital stay and survival up to 5 years of age in many cases. ${ }^{27-30}$ Even if children are orphaned they will incur less cost to the state and remaining relatives (who are their most likely carers) if they are uninfected with HIV.

\section{Generalisation of results}

The generalisability of our results is best illustrated by sensitivity analyses. Settings with low rates of HIV infection would seem to be the most obvious relative contraindication to intervention for economic reasons. Elimination of breast feeding in settings with high infant mortality or where there is a strong protective effect of breast feeding would not be recommended as more deaths would be caused than saved by formula feeding. We believe, however, that regardless of setting women who test positive for HIV during pregnancy should be given information to enable them to make an informed decision as to how to feed their infants. The antiretroviral interventions were generally more robust in the face of changes in the various settings, with or without formula feeding. Recently published results from an antiretroviral trial in breastfeeding women support this finding. ${ }^{2}$ The scope of this paper does not allow description of all possible combinations. We would encourage anyone interested in applying the model to local conditions to contact the authors directly.

While mathematical models are useful in highlighting the key determinants of an intervention's likely
Key messages

- Despite favourable trial results many developing countries are unsure of the appropriateness of implementing antenatal screening and prevention programmes for vertical transmission of HIV

- Screening and administration of antiretroviral drugs around birth is likely to be a cost effective intervention across a wide range of settings, irrespective of mode of feeding

- Recommendation of formula feeding for babies of HIV positive mothers is contraindicated in areas of high infant mortality

- Simulation modelling might assist decision makers to weigh up the relative advantages and disadvantages of strategies for prevention of vertical transmission in their own areas

- Pilot projects are required to test feasibility and acceptability of such strategies

suitability, they cannot deal with either feasibility or unexpected adverse effects that may occur. In South Africa, where HIV seroprevalence is high, infant mortality is generally below $50 / 1000$, there is a high level of spending on HIV infected children, and the infrastructure is relatively sophisticated, it would seem inadvisable to delay piloting such an intervention.

We thank participants at a number of conferences and two anonymous referees for suggestions. Thanks are also due to the paediatrics department at Chris Hani Baragwanath Hospital, the South African National Department of Health, and the Gauteng Provincial Department of Health for data provided. Any errors remain the responsibility of the authors.

Contributors: NS had the original idea and developed the model and contributed to writing the paper. KZ supplied data on utilisation rates and costs for HIV infected children and contributed to writing and editing the paper. AK estimated the costs of antiretroviral treatment and other interventions and contributed to writing the paper. GG helped to develop the work, provided published and unpublished data, and contributed to writing the paper. NS is the guarantor for the study.

Funding: None.

Competing interests: None declared.

1 Stover J, Way P. Projecting the impact of AIDS on mortality. AIDS 1998;12:S29-39.

2 Dabis F, Msellati P, Meda N, Welffens-Ekra C, You B, Olivier M, et al. 6-month efficacy, tolerance, and acceptability of a short regimen of oral zidovudine to reduce vertical transmission of HIV in breastfed children in Cote d'Ivoire and Burkino Faso: a double-blind placebo-controlled multicentre trial. Lancet 1999;353:786-92.

3 Wiktor SZ, Ekpini E, Karon JM, Nkengasong J, Maurice C, Severin ST, et al. Short-course oral zidovudine for prevention of mother-to-child transmission of HIV-1 in Abidjan, Cote d'Ivoire: a randomised trial. Lancet 1999;353:781-5

4 Shaffer N, Chuachoowong R, Mock PA, Bhadrakom C, Siriwasin W, Young NL, et al. Short-course zidovidine for perinatal HIV-1 transmission in Bang

5 Ratcliffe J, Ades AE, Gibb D, Sculpher MJ, Briggs AH. Prevention of mother-to-child transmission of HIV-1 infection: alternative strategies and their cost-effectiveness. AIDS 1998;12:1381-8.

6 Nicoll A, Newell ML, Von Praag E, Van de Perre P, Peckham C. Infant feeding policy and practice in the presence of HIV-1 infection. AIDS 1995;9:107-19.

7 Mofenson LM. Interaction between timing of potential human immunodeficiency virus infection and the design of preventive and therapeutic interventions. Acta Paediatr Suppl 1997;421:1-9.

8 Connor EM, Sperling RS, Gelber R, Kiselev O, Scott G, O'Sullivan MJ, et al. Reduction of maternal-infant transmission of human immunodeficiency virus type 1 with zidovudine treament. Pediatric AIDS clinical trials group protocol 076 study group. N Engl J Med 1994;331:1173-80.

9 Mayaux MJ, Teglas JP, Mandelbrot L, Berrebi A, Gallais H, Matheron S, et al. Acceptability and impact of zidovudine prevention on mother-to-child HIV-1 transmission in France. J Pediatr 1997;131:857-62. 
10 Dunn DT, Newell ML, Mayaux, Kind C, Hutto C, Goedert JJ, et al. Mode of delivery and vertical transmission of HIV-1: a review of prospective studies. Perinatal AIDS collaborative transmission studies. J AIDS Hum Retrovirol 1994;7:1064-6.

11 Sculpher MJ, Gibb D, Ades AE, Ratcliffe J, Duong T. Modelling the costs of paediatric HIV infection and AIDS: comparison of infected children of paediatric HIV infection and AIDS: comparison of infected child
born to screened and unscreened mothers. AIDS 1998;12:1371-80.

12 Biggar RJ, Miotti PG, Taha, Mtimavalye L, Broadhead R, Justesen A, et al. Perinatal intervention trial in Africa: effect of birth canal cleansing intervention to prevent HIV transmission. Lancet 1996;347:1647-50.

13 Semba RD, Miotti PG, Chipangwi J, Saah AJ, Canner JK, Dallabetta GA, et al. Maternal Vitamin A deficiency and mother-to-child transmission of HIV-1. Lancet 1994:343:1593-7.

14 UNAIDS and World Health Organisation. Guidance modules on anti-retroviral treatments-module 6. The use of antiretroviral drugs to reduce mother to child transmission of HIV. Geneva: UNAIDS/WHO, 1998.

15 Marseilles E, Kahn JG, Saba J. Cost-effectiveness of anti-retroviral drug therapy to reduce mother-to-child HIV transmission in sub-Saharan Africa. AIDS 1998;12:939-48.

16 Mansergh G, Haddix AC, Steketee RW, Nieburg PI, Hu DJ, Simonds RJ, et al. Cost-effectiveness of short-course zidovudine to prevent perinatal HIV type 1 infection in a sub-Saharan African developing country setting. JAMA 1996;276:139-45.

17 Wilkinson D, Floyd K, Gilks CF. Antiretroviral drugs as a public health intervention for pregnant women in rural South Africa: an issue of costeffectiveness and capacity. AIDS 1998;12:1675-82.

18 Centres for Disease Control and Prevention. Administration of zidovudine during late pregnancy and delivery to prevent perinatal HIV zidovudine during late pregnancy and delive 1998:47:151-4.

19 Department of Health and Population Development, South Africa. Seventh national HIV survey of women attending antenatal clinics of the public health services in the Republic of South Africa, October/ November 1996. Epidemiological Comments 1996;23:4-16.

20 Harrison D, Nielson M, ed. South African health review-1995. Durban: Health Systems Trust and the Henry J Kaiser Foundation, 1995.

21 World Bank. World development report 1993-investing in health. New York: Oxford University Press, 1993.

22 Wagstaff L, de Wet T, Anderson A. Infant feeding: birth to ten. Urbanisation and Health Newsletter 1993;18:9-16.
23 Ross SM, van Middelkoop A, Khoza NC. Breast feeding practices in a black community. S Afr Med J 1983;63:23-5.

24 Central Statistical Service. Statistics in brief-1997. Pretoria: Central Statistical Service, 1997.

25 Cunningham AS, Jelliffe DB, Patrice Jelliffe EF. Breast-feeding and health in the 1980s: a global epidemiologic review. J Pediatr 1991;118:659-66.

26 Kinghorn AW. Projections of the costs of anti-retroviral interventions to reduce mother-to-child transmission of HIV in the South African public sector. Johannesburg: HIV Management Services Technical Report, 1998.

27 Zwi KJ, Pettifor JM, Söderlund RN. Paediatric hospital admissions at a South African urban regional hospital: the impact of HIV 1992-1997. Ann Trop Paed (in press).

28 Söderlund N. Likely costs of hospital care benefits to be covered by a Social Health Insurance fund-a report to the National Department of Health. Johannesburg: Centre for Health Policy, 1997.

29 Söderlund N, Peprah E. An essential hospital package for South Africa-selection criteria, costs and affordability. Johannesburg: Centre for Health Policy, 1998. (Monograph No 52.)

30 Brown M, van den Heever A. Report by the consultants on the existing expenditure trends and functional costs to support the function analysis and rationalisation programme in terms of the National Health Plan and the Reconstruction and Deudopment Prograne. Johannesburg: PWV Province struction and Development Programme. Joha

31 Regional Health Management Information System (ReHMIS). Pretoria: National Department of Health of South Africa, 1995.

32 Briggs A, Sculpher M. An introduction to Markov modelling for economic evaluation. Pharmacoeconomics 1998;13:397-409.

33 Tess BH, Rodrigues LC, Newell ML, Dunn DT, Lago TD. Infant feeding and risk of mother-to-child transmission of HIV in Sao Paulo State, Brazil. Sao Paulo collaborative study for vertical transmission of HIV-1. J AIDS Hum Retrovirol 1998; 19:189-94.

34 Bertolli J, St Louis ME, Simonds RJ, Nieburg P, Kamenga M, Brown C, et al. Estimating the timing of mother-to-child transmission of human immunodeficiency virus in a breastfeeding population in Kinshasa, Zaire. J Infect Dis 1996;174:722-6.

35 UNAIDS and World Health Organisation. Guidance modules on antiretroviral treatments-module 2. Introducing antiretroviral treatments into health systems: economic considerations. Geneva: UNAIDS/WHO, 1998.

(Accepted 30 March 1999)

\title{
Universal HIV screening of pregnant women in England: cost effectiveness analysis
}

\author{
M J Postma, E J Beck, S Mandalia, L Sherr, M D S Walters, H Houweling, J C Jager
}

Papers pp 1650,

\section{0}

National Institute of Public Health and the Environment, PO Box 1,3720 BA Bilthoven,

Netherlands

Department of Health Services Research

M J Postma, econometrician J C Jager, biomathematician

Department of Infectious Diseases Epidemiology

H Houweling, epidemiologist continued over

BMJ 1999;318:1656-60

\begin{abstract}
Objective To estimate the cost effectiveness of universal, voluntary HIV screening of pregnant women in England.

Design Cost effectiveness analysis. Cost estimates of caring for HIV positive children were based on the stage of HIV infection and calculated using data obtained from a London hospital between 1986 and 1996. These were combined with estimates of the health benefits and costs of antenatal screening so that the cost effectiveness of universal, voluntary antenatal screening for HIV infection in England could be estimated.

Main outcome measures Lifetime, direct costs of medical care of childhood HIV infection; life years gained as a result of the screening programme; net cost per life year gained for different pretest counselling costs; and different prevalence rates of pregnant women who were unaware that they were HIV positive.
\end{abstract}

Results Estimated direct lifetime medical and social care costs of childhood HIV infection were $£ 178300$ using a 5\% discount rate for time preference (1995-6 prices). In high prevalence areas screening pregnant women for HIV is estimated to be a cost effective intervention with a net cost of less than $£ 4000$ for each life year gained. For areas with comparatively low prevalence rates, cost effectiveness could be less than $£ 20000$ per life year gained, depending on the number of pregnant women who are unaware that they are infected and local screening costs.

Conclusions Our results confirm recent recommendations that universal, voluntary antenatal HIV screening should be implemented in the London area. Serious consideration of the policy should be given for other areas in England depending on local prevalence and screening costs.

\section{Introduction}

In England the uptake of antenatal HIV screening is comparatively low despite the existence of guidelines on antenatal screening for pregnant women. ${ }^{1}$ Detection of HIV infection in pregnant women allows the risk of mother to child transmission to be reduced..$^{2-4}$ This study analyses the cost effectiveness of an antenatal HIV screening programme.

\section{Methods}

We assessed the cost effectiveness of universal, voluntary HIV screening of pregnant women in England in terms of healthcare costs to the NHS. A staged, progression of disease model was developed 